\title{
PUBLICIDADE ILÍCITA: as celebridades que dela fazem parte
}

\author{
Nathalie Kuczura Nedel ${ }^{1}$
}

\begin{abstract}
RESUMO: As celebridades endossam diversas publicidades, através de seus depoimentos ou de sua imagem. O grande problema surge quando este anúncio é enganoso ou abusivo, ou seja, quando se está diante de uma publicidade ilícita. Como é sabido, deve ser respeitado o princípio da boa-fé objetiva nas relações de consumo, bem como todos aqueles que induzirem o consumidor a tomar a sua decisão serão civilmente responsáveis, desde que estejam presentes a ação ou omissão; o dano; o nexo causal e, em alguns casos, muito raramente, a culpa ou o dolo. Por isto, a celebridade poderá ser demandada em juízo caso faça parte de um anúncio ilícito.

PALAVRAS-CHAVE: Publicidade ilícita; celebridades; responsabilidade civil.
\end{abstract}

\section{UNLAWFUL ADVERTISING: the celebrities who make part of it}

ABSTRACT: Celebrities endorse various advertisements, through their testimonies and their image. The big problem comes up when this ad is deceitful or abusive, that is, when we are facing an unlawful advertising. As it is known, the principle of objective good faith in consumption connections must be respected, as well as those who induce consumers to make up their mind shall be civilly responsible since the action or omission are present, also the damage; the causal link, and in some cases, very rarely the fault or the conscious act. Therefore, the celebrity may be sued in court case is part of an unlawful advertisement.

KEY-WORDS: Unlawful advertising; celebrities; civil responsability.

\section{INTRODUÇÃO}

Comumente, as publicidades veiculadas, para obter um melhor resultado, apresentam uma celebridade, um perito, ou até mesmo desenhos famosos, discorrendo, comentando, fazendo um parecer favorável acerca do produto ou serviço que está sendo exposto. Por vezes, estes não emitem qualquer parecer, mas, tão-somente, emprestam a sua imagem, para que aquele determinado produto seja associado àquela celebridade.

Quando uma publicidade é feita por um artista, o consumidor relaciona o produto com a admiração, riqueza, sucesso, beleza, juventude, alegria e notoriedade que tem a celebridade nela estampada. Desta forma, o consumidor é influenciado, de forma consciente ou inconsciente, diretamente na sua escolha.

O grande problema surge quando as informações repassadas através da publicidade ao consumidor são omissas ou errôneas, caso em que a celebridade causa

\footnotetext{
${ }^{1}$ Estudante, Universidade Federal de Santa Maria. nathinkn@ hotmail.com.
} 
uma falsa segurança ao consumidor. Nesta hipótese, cabe analisar qual a responsabilidade daquele artista, perito, especialista que fez parte da publicidade.

A celebridade quando participa de uma publicidade atua como "garante", ou seja, uma vez cedendo a sua imagem, o seu depoimento ou o seu testemunho, qualquer informação errada ou faltosa, será, também, imputada a mesma.

\section{A RESPONSABILIDADE CIVIL DAS CELEBRIDADES}

Primeiramente, cabe fazer referência a "teoria da confiança", que é a utilizada nos casos de publicidade enganosa endossada por celebridades. Para esta teoria quando o titular da publicidade fizer com que outra pessoa possa nele confiar, seja através de seus testemunhos ou comportamento, não poderá desiludi-la, uma vez que isto implicaria em violação ao princípio da boa-fé objetiva.

Logo, em que pese, não tenha a Lei Consumeirista tratado especificamente das celebridades estas possuem direitos e deveres perante os consumidores e entre os seus deveres estão o de agir com lealdade e transparência, sendo obrigadas a transmitir mensagens verídicas e completas.

Assim, apresentando algum produto que não contenha as características anunciadas, todos aqueles que de forma consciente participaram da veiculação da mensagem atentatória podem ser demandados em juízo pelo consumidor. Entre este, por óbvio, encontram-se as celebridades.

Nesta senda, vislumbra-se o cuidado que a celebridade deve ter ao afirmar algo a respeito de algum produto ou serviço ou de ceder a sua imagem para ser nele veiculada. Entretanto, sabe-se que em muitos casos as pessoas com notoriedade pública sequer conhecem o produto e dão, por exemplo, o seu testemunho favorável acerca do mesmo. Nestes casos, há violação do CDC e, igualmente, do Código de Auto-Regulamentação Publicitária, dando ensejo ao dever indenizar da celebridade.

Para ilustrar tal situação o autor Guimarães (2001, p. 159), relata o exemplo do anúncio das pílulas Microvlar, o qual foi feito pela atriz Maitê Proença, que na oportunidade, garantiu e atestou a qualidade da mesma. Contudo, logo após a veiculação da publicidade foram descobertas inúmeras irregularidades com o produto, passando-se a questionar sua eficácia. Diante dos fatos, a atriz asseverou que sua imagem havia sido prejudicada, porém afirmou que se a empresa fabricante do 
medicamento quisesse contratá-la novamente, deveria pagar um cachê muito mais elevado.

Nesta situação é visível o descaso da atriz com o consumidor, sendo mais relevante o numerário que será recebido pela publicidade realizada. Os consumidores que se sentiram lesados com a publicidade acima referida poderiam ajuizar uma ação de indenização em desfavor de Maitê Proença e/ou do laboratório que produzia tal pílula.

Fica claro, que a celebridade terá responsabilidade solidária com o fornecedor/ construtor/ fabricante. Sendo irrelevante para a condenação qual o grau de participação para o dano de cada um dos envolvidos, pois perante o consumidor todos responderão pela totalidade da dívida, podendo, posteriormente, aquele que pagou ajuizar uma ação regressiva em face do real culpado. ${ }^{2}$

Para que a celebridade seja responsabilizada é necessário que estejam presentes os elementos formadores da responsabilidade civil: ação ou omissão, dano, nexo causal e, em alguns casos, dolo ou culpa.

A pessoa que faz a o anúncio para ser responsabilizada por sua ação ou omissão, deverá, além dos elementos já citados, ser uma pessoa reconhecida publicamente, bem como deve a mesma ser identificada na publicidade. No mesmo sentido, é a decisão da Apelação Cível no 1563624000 do TJ-SP, na qual a ação é julgada improcedente, pois na publicidade apenas era visível os olhos da "modelo" e esta sequer tinha fama, ou seja, não era conhecida publicamente.

A conduta comissiva ${ }^{3}$ da celebridade se caracteriza quando esta disser algo, ou mesmo sem nada falar, demonstrar algo falso, que possa induzir o consumidor em erro, ou quando o anúncio atentar contra a moralidade, os bons costumes, etc. Por outro lado, a conduta omissiva ${ }^{4}$, se dá quando uma informação relevante não é passada ao consumidor.

Outrossim, além de existir uma das condutas supra mencionadas, a celebridade deverá ter um benefício com o anúncio. Este pode ser direto, que normalmente se dá pelo cachê, ou indireto, que ocorre quando a remuneração é destinada a um órgão

\footnotetext{
${ }^{2}$ Cabe salientar que, como é sabido, não cabe denunciação à lide, pois quando aplicado o CDC as únicas formas de intervenção de terceiros aceitas são: a assistência e chamamento ao processo em caso de seguro.

${ }^{3}$ Como exemplo: o anúncio do "Vitassay", em que Edson Arantes da Nascimento dá sua opinão acerca do produto

${ }^{4}$ A título de exemplo pode-se citar a publicidade feita por Antônio Fagundes da empresa "Boi Gordo", na qual o ator não faz qualquer menção aos riscos do negócio.
} 
diretamente ligado a celebridade, é o acontece quando esta doa o seu cachê para uma instituição beneficente.

É preciso, também que exista dano ${ }^{5}$, para que a responsabilidade se configure. Este pode ser individual ou transindividual, moral ou patrimonial. No caso da publicidade ilícita há a caracterização do dano coletivo, uma vez que a veiculação do anúncio pode atingir um grupo determinado de pessoas ou indivíduos indeterminados.

Assim, a simples veiculação da publicidade ilícita já gera o dano a todos expostos a mesma. Não é preciso para que este se configure que exista, de fato, um dano patrimonial, pois a divulgação da publicidade ilícita, por si só, já gera àquele que com ela teve contato, danos morais, ou seja, não se exige que o consumidor seja enganado efetivamente. $^{6}$

Caracterizado o dano moral, deverá o julgador fixar o valor da condenação, atentando para a extensão do dano, grau de culpa do agente, bem como para um valor que desestimule a prática deste ato abusivo. Quando a demandada for a celebridade, que endossou o anúncio, a indenização não se limitará aos seus ganhos.

Enquanto a existência de dano moral se presume, pela simples divulgação da publicidade, o dano patrimonial deverá ser provado pela vítima.

Outro elemento imprescindível é o nexo causal, ou seja, para que a celebridade seja responsabilizada pelos danos, deverá existir um liame entre a sua conduta e o dano gerado. No que tange, as pessoas com notoriedade pública, presume-se que, independentemente do comportamento do anunciante/ fabricante/ construtor/ fornecedor, influenciará a escolha do consumidor. Desta forma, há a presunção de causalidade, porém pode a celebridade provar que a sua presença na publicidade em nada influenciou o consumidor.

Por fim, refere-se à culpa ou dolo. Como é sabido, o CDC adotou a teoria do risco, em que, em regra, não é preciso analisar a culpa, havendo os três elementos citados anteriormente, já surge o dever de indenizar, salvo quando na relação consumeirista uma das partes for profissional liberal, caso em que a responsabilidade será subjetiva e deverá ser analisada a culpa ou dolo.

Em que pese, alguns doutrinadores arguirem que as celebridades são profissionais liberais e que, por conseguinte, deve-se aplicar a responsabilidade subjetiva, a maioria dos autores da área entendem que é aplicável a responsabilidade

\footnotetext{
${ }^{5}$ Diminuição ou subtração de um bem tutelado juridicamente.

${ }^{6}$ Neste sentido: Paulo Jorge Scartezzini Guimarães, Maria Luiza de Sabóia Campos e Nelson Nery.
} 
objetiva, pois as celebridades não se enquadram no conceito de profissional liberal ${ }^{7}$, uma vez que, geralmente, não são contratadas por causa de suas características intelectuais ou técnicas, bem como não são contratadas pelos consumidores intuito personae.

Uma vez configurada a responsabilidade civil da celebridade, ela poderá se excutir da mesma, alegando que não participou do anúncio, que a publicidade não é ilícita, que inexistiu dano, que inexiste nexo de causalidade, que o consumidor tinha conhecimento da enganosividade ou abusividade do anúncio ou que a decisão do consumidor não se deu pela sua participação na publicidade.

Em regra, a celebridade será demandada através de uma ação de indenização. Entretanto, nada impede que seja demandada para cumprir uma obrigação assumida, ou para que faça uma contrapropaganda.

\section{CONSIDERAÇÕES FINAIS}

É de suma importância saber se as celebridades podem ser responsabilizadas pelas publicidades ilícitas que participam, pois quando, por exemplo, o anunciante deixar de existir de fato ou deixar de ter patrimônio suficiente para arcar com a dívida, poder-se-á receber a indenização da celebridade. Claro, que mesmo que não ocorra qualquer destas hipóteses a celebridade responderá caso demandada, uma vez que a sua responsabilidade é solidária.

A doutrina pouco trata deste tema, porém é bastante vasto e interessante, além de ser vislumbrado na prática todos os dias pelos consumidores. Por ser conhecido e estudado por poucos, raramente, vê-se ações em que a ré seja alguém com notoriedade pública. Entretanto, a tendência, hodiernamente, é que cada vez mais as celebridades sejam demandadas e responsabilizadas por publicidades que endossam.

\section{REFERÊNCIAS BIBLIOGRÁFICAS}

BENJAMIN, Antônio Herman V.; MARQUES, Claudia Lima; BESSA, Leonardo Roscoe. Manual de direito do consumidor. $2^{\mathrm{a}}$ Ed. São Paulo: Editora Revista dos Tribunais, 2009.

\footnotetext{
${ }^{7}$ Profissionais liberais são aqueles que exercem a sua profissão de forma autônoma e que são dotados de características intelectuais ou técnicas especiais
} 
GUIMARÃES, Paulo Jorge Scartezzini. A publicidade ilícita e a responsabilidade civil das celebridades que dela participam. São Paulo: Editora Revista dos Tribunais, 2001.

OLIVEIRA, Josinaldo Leal de. A Função Social das Celebridades. In: Jus Navigandi. Teresina: 2008. Disponível em: <http://jus2.uol.com.br/doutrina/texto.asp?id=12404>. Acesso em 13 jun. 2009. 